American Journal of Applied Sciences 4 (2): 60-65, 2007

ISSN 1546-9239

(C) 2007 Science Publications

\title{
Fuzzy Based Energy Management of a Domestic Photovoltaic Panel
}

\author{
${ }^{1,2}$ Maher Chaabene, ${ }^{1,2}$ Mohsen Ben Ammar and ${ }^{3}$ Ahmed Elhajjaji \\ ${ }^{1}$ The high institute of technological studies (ISET) - Sfax, Tunisia. \\ ${ }^{2}$ Unité de commande de machines et réseaux de puissance CMERP -ENIS-Tunisia. \\ ${ }^{3}$ Centre de Robotique, d'électrotechnique et d'automatique CREA France
}

\begin{abstract}
This study introduces a new switching mean giving a real time optimum connection mode of domestic apparatus on either the electrical grid or a photovoltaic panel (PVP) output. A fuzzy algorithm makes the decision which ensures the optimal energy management basing on the PVP generation and apparatus states with respect to energy save criteria. Validation was driven on a $1 \mathrm{~kW}$ peak $(\mathrm{kWp})$ PVP and domicile apparatus of different powers installed at the Energy and Thermal Research Centre (CRTEn) in the north of Tunisia. Results confirm that energy save during daylight reaches $90 \%$ of the PVP generated energy.
\end{abstract}

Key words: Energy management, fuzzy decision, photovoltaic, energy saves

\section{INTRODUCTION}

Household electric apparatus have become increasingly diversified during last years, which has led to an increase in energy need. Yet, the energy crisis does not cease being accentuated. These two constraints yield a heavy additional financial expense to the consumer. Several researches have confirmed that more than $60 \%$ of total useful energy represents buildings electric energy consumption ${ }^{[1]}$, much of which could be recovered by integrating renewable energy and by formulating adequate energy management strategies inside buildings. For this reason, the exploitation of photovoltaic electricity has become an important issue of debate. Thus, three operating modes of PVP are distinguished: stand alone, grid connected and hybrid mode.

In stand alone mode, the PVP represents the only source of electric energy for equipment. This mode is adopted when the network is not available or when the equipment function depends only on the sun occurrence (pumping, lighting, air-conditioning, heating, etc.). Research interests are essentially related to the modelling $^{[2-5]}$, the optimization ${ }^{[6]}$ and the adaptation system $^{[7]}$ of the PVP supply according to equipment needs. As for researches carried out on grid connected PVP, they generally deal with system assessment and characterization depending on site climate ${ }^{[8,9]}$. Finally, the hybrid mode is the combination of PVP with other energy sources. Published studies proposed either new design of PVP hybrid energy systems ${ }^{[10]}$ or PVP hybrid power systems sizing ${ }^{[11]}$. For all operating modes, other researches developed energy management strategies so as to offer optimum function ${ }^{[12-14]}$. Nevertheless, the main problem in photovoltaic applications remains the battery cost and the protection and synchronization systems of grid connected $\mathrm{PVP}^{[2]}$ essentially when using large scale photovoltaic power station.

In this study, a new operating mode is proposed where a domestic PVP is considered as a complementary electric source to supply energy to domestic apparatus. There is no need for batteries neither for grid protection system. The installation incorporates a $1 \mathrm{kWp}$ PVP, six apparatus of powers varying between $50 \mathrm{~W}$ and $500 \mathrm{~W}$ and a switching unit. A fuzzy decision making algorithm gives orders to the switching unit so as to connect each device either to the PVP output or to the electric grid. The decision of the appropriate connection mode is based on criteria that offer maximum exploitation of the energy delivered by the PVP during daylight depending on load demand without disturbing however apparatus' function. The energy management system is implemented at the Energy and Thermal Research Centre (CRTEn) in the north of Tunisia since Jannuary 2005. The results validation is illustrated over four days representing the seasons of the year. Furthermore an energy audit was established and showed that the proposed system is able to bring an energy save during daylight up to $90 \%$ of the PVP generated energy.

The management criteria: The system studied in the present work aims to offer a utility decision tool on the connection way of domestic apparatus either on a domestic PVP output or on the electric grid. The decision is made in real time on the basis of the following criteria:

* To guarantee continuous electric supply for active apparatus.

* To minimize the power drawn from the electric grid.

* To maximise connection time of PVP connected apparatus so as to avoid relays' commutation.

* To reserve a power margin of $+10 \%$ for each PVP 
connected apparatus which guarantees its continuous function face to possible climate perturbation.

* To respect apparatus priority: Since an apparatus is connected to PVP output, it has priority to remain connected.

* To give apparatus of lower power the higher priority to be connected to PVP output.

The two available sources of electric energy are exploited to provide power for apparatus through fuzzy commands given to apparatus relays with respect of the above decision criteria. Figure 1 traces the synoptic schema of the proposed approach.

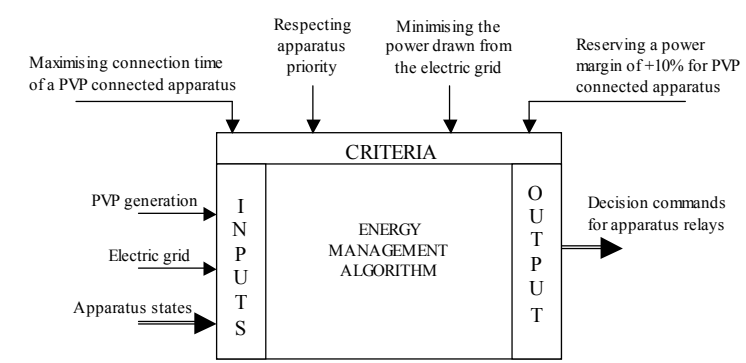

Fig. 1: The synoptic schema of the proposed approach

The fuzzy management algorithm: Since the energy management approach uses fuzzy logic, its algorithm is based on three steps: the knowledge base of the expert, the fuzzification and the inference diagram ${ }^{[16]}$.

The knowledge base of the expert: The approach handles a multi criteria resolution for which three fuzzy partitions are judged necessary:

According to apparatus states: The fuzzy partition of apparatus states is composed of $\mathrm{N}_{\mathrm{s}}=2$ fuzzy subsets. $A_{j i}=(O F F, O N)$ is the $i^{\text {th }}$ fuzzy subset, $i=\{1,2\}$, of the $\mathrm{j}^{\text {th }}$ apparatus, $\mathrm{j}=\{1,2,3,4,5,6\}$. These subsets cover the fuzzy domain $X=[0,1]$ and verify $\forall x=E R_{j} \in X, \quad \sum_{i=1}^{N s} \mu_{A_{j i}}(x)=1$, where $\quad E_{j}$ is the state of the $\mathrm{j}^{\text {th }}$ apparatus and $\mu_{\mathrm{Aji}}$ the membership function.

According to 1 KWp PVP generation: Here the fuzzy partition is composed of $N_{s}=20$ fuzzy subsets $B_{l}=(A, B, \ldots, S), l=\{1,2, \ldots, 20\}$, which cover the fuzzy domain $Y=[0,1000]$. These fuzzy subsets verify $\forall y=P_{l} \in Y, \quad \sum_{l=1}^{N s} \mu_{B_{l}}(y)=1$, where $P_{l}$ is the PVP generation and $\mu_{B_{l}}$ is the membership function.

According to relays control: The relays command requires $N_{s}=2$ fuzzy subsets. $C_{j k}=($ grid, $P V P)$ is the $k^{\text {th }}$ fuzzy subset, $k=\{1,2\}$, of the $j^{\text {th }}$ apparatus relay. These fuzzy subsets cover the fuzzy domain $Z=[0,1]$ and verify $\forall z=E S_{j} \in Z, \quad \sum_{k=1}^{N_{s}} \mu_{C_{j k}}(z)=1$, where $E S_{j}$ is the command given to the $j^{\text {th }}$ apparatus relay and $\mu_{C_{j k}}$ is the membership function.

The general rules format is:

$\operatorname{IF}\left(\mathrm{ER}_{1}\right.$ is $\left.\mathrm{A}_{1 \mathrm{i}}\right)$ and $\left(\mathrm{ER}_{2}\right.$ is $\left.\mathrm{A}_{2 \mathrm{i}}\right)$ and

$\left(E R_{3}\right.$ is $\left.A_{3 i}\right)$ and $\left(E R_{4}\right.$ is $\left.A_{4 i}\right)$ and

$\left(\mathrm{ER}_{5}\right.$ is $\left.\mathrm{A}_{5 \mathrm{i}}\right)$ and $\left(\mathrm{ER}_{6}\right.$ is $\left.\mathrm{A}_{6 \mathrm{i}}\right)$ and $\left(\mathrm{P}_{1}\right.$ is $\left.\mathrm{B}_{1}\right)$

THEN $\left(\mathrm{ES}_{1}\right.$ is $\mathrm{C}_{1 \mathrm{k}}$ ) and $\left(\mathrm{ES}_{2}\right.$ is $\mathrm{C}_{2 \mathrm{k}}$ ) and

$\left(\mathrm{ES}_{3}\right.$ is $\left.\mathrm{C}_{3 \mathrm{k}}\right)$ and $\left(\mathrm{ES}_{4}\right.$ is $\left.\mathrm{C}_{4 \mathrm{k}}\right)$ and

$\left(\mathrm{ES}_{5}\right.$ is $\left.\mathrm{C}_{5 \mathrm{k}}\right)$ and $\left(\mathrm{ES}_{6}\right.$ is $\left.\mathrm{C}_{6 \mathrm{k}}\right)$

The fuzzification: The determined fuzzy partitions lead to the determination of the following membership functions:

$\mu_{\mathrm{A}_{\mathrm{ji}}}(\mathrm{x})=\max \left(0,1-\frac{\left|\mathrm{x}_{\mathrm{j}}-\mathrm{x}_{0 \mathrm{i}}\right|}{\varepsilon_{\mathrm{x}_{0 \mathrm{i}}}}\right)$ :

The membership function of the apparatus,

$\mu_{B_{1}}(y)=\max \left(0,1-\frac{\left|y-y_{01}\right|}{\varepsilon_{y_{01}}}\right):$

The membership function of PVP generation,

$\mu_{\mathrm{C}_{\mathrm{jk}}}(\mathrm{z})=\max \left(0,1-\frac{\left|\mathrm{z}_{\mathrm{j}}-\mathrm{z}_{0 \mathrm{k}}\right|}{\varepsilon_{\mathrm{z}_{0 \mathrm{k}}}}\right)$ :

The membership function of the relays states, (3) where $x_{0 i}, y_{0 l}, z_{0 k}$ are respectively the real values of the variables $x_{j}, y, z_{j}$ in their membership domains and $\varepsilon_{x_{0 i}}, \varepsilon_{y_{0 l}}, \varepsilon_{z_{0 k}}$ are respectively the range values of $x_{0 i}, y_{0 l}, z_{0 k}$.

Inference diagram: By means of the rules' base already established and the membership functions obtained by the fuzzification operation, the weightings $w_{j k}$ are computed according to Mamdani ${ }^{[17]}$.

Acquire $P_{l}$

$l=E\left(\frac{P_{l}}{50}\right):$ calculate the fuzzy subsets' number of the PVP generation.

Initialization: $E S_{j}=0(j=1$ to 6$)$ : all apparatus connected on the grid.

$E S_{0}=0, P_{0}=0=0$ : start pointers

Repeat for $j=1$ to 6 
\{Acquire $j^{\text {th }}$ apparatus state $E R_{j}$

Fuzzification

\section{Inference diagram}

$P_{l}=P_{l}-P_{j-1} * E S_{j-1}: P_{l}$ is the PVP generation, $P_{j}$ is

the operating power of the $j^{\text {th }}$ apparatus.

$w_{j 1}=\min \left(\mu_{A_{j 1}}, \mu_{B_{l}}\right)$

$w_{j 2}=\min \left(\mu_{A_{j 2}}, \mu_{B_{l+1}}\right)$

$\mu_{C^{\prime}{ }_{j 1}}=\min \left(w_{j 1}, \mu_{c_{j 1}}\right)$

$\mu_{C^{\prime}{ }_{j 2}}=\min \left(w_{j 2}, \mu_{c 2}\right)$

$\mu_{C_{j}}=\max \left(\mu_{C^{\prime}{ }_{j 1}}, \mu_{C^{\prime}{ }_{j 2}}\right)$

Defuzzification: Compute $E S_{j}$ (the $j^{\text {th }}$ apparatus relay command) using the centroid method .

The system implementation: The system is implemented at the Energy and Thermal Research Centre (CRTEn) in the north of Tunisia since January 2005. It includes:

* $\quad 1 \mathrm{kWp} \mathrm{PVP}$ and the electric grid as energy sources. The PVP is equipped with a Maximum Power point Tracker (MPPT) ${ }^{[13]}$ which is an electronic device that monitors PVP generation to operate near its maximum power point along the $\mathrm{I}-\mathrm{V}$ curve and an inverter that provides the same output voltage as the electric grid $(230 \mathrm{~V} / 50 \mathrm{~Hz})^{[7]}$.

* Six household apparatus of different power: 50, $100,200,300,400$ and $500 \mathrm{~W}(230 \mathrm{~V} / 50 \mathrm{~Hz})$. Each one is controlled by a two position relay in order to be connected either to the PVP output or to the electric grid.

Figure 2 shows the connection schema of the system components. The decision centre is composed of a personnel computer equipped with a data acquisition and control card. The PVP generation $\left(P_{l}\right)$ is calculated on the basis of a published $1 \mathrm{kWp}$ PVP validated model $^{[15]}$ :

$\mathrm{P}_{1}=20\left(\begin{array}{l}3.33+1.210^{-3}\left(\frac{\mathrm{I}}{1000}\right)\left(\mathrm{T}_{\mathrm{a}}+\frac{\mathrm{I}}{40}-25\right) \\ +3.35\left(\frac{\mathrm{I}}{1000}-1\right)\end{array}\right) \mathrm{u}_{\mathrm{pv}}$

where $I$ and $T a$ are respectively the acquired solar radiation ambient temperature measured at the surface of the PVP. $u_{p v}$ is the PVP output voltage fixed to $12 \mathrm{~V}$ by the MMPT device. The algorithm is implemented using the Matlab software as a programming tool.

After implementation, the system has been tested during the year 2005. All its input/output $\left(T a, I, E R_{j}, E S_{j}\right)$ have been daily recorded using a time step of 5 minutes. A power audit has been also

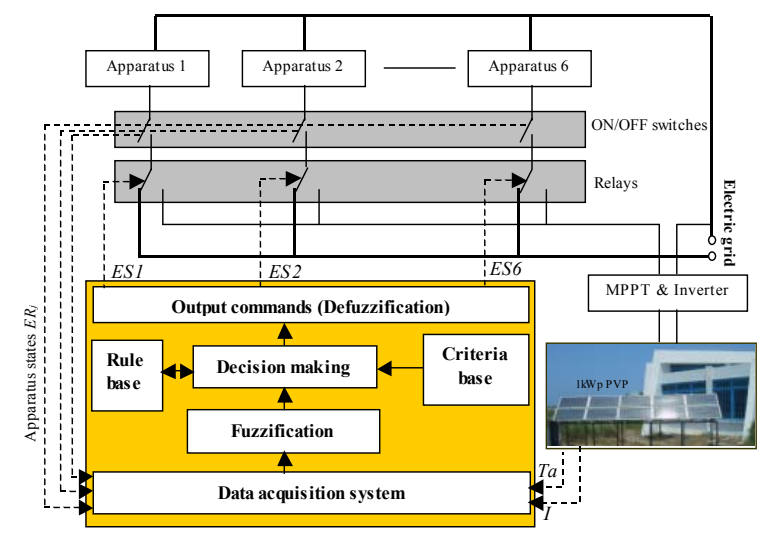

Fig. 2: System components and implementation

established in order to determine the system performance. Even so, for clearness reason the system behaviour and performance is given only for four days representing the year's seasons. Figure 3 shows the fuzzy commands timing of relays during daylight. During function, all apparatus were switched on in order to evaluate the contribution of the PVP generation to the whole installation. By examining the fuzzy decisions, it can be easily deduced that most commutations between grid and PVP output are observed at apparatus of lower power. This is due to the above management constraints (\$2) which affect the higher priority to apparatus of lower power in order to recuperate the remaining power of the ones of higher power. As well, commutations can be seen at apparatus of high power when PVP generation is available (June and September). In this case these commutations are limited to the time around midday. Finally, only lower power apparatus are connected to PVP output while PVP generation is weak (December).

Since it holds the lower priority, the apparatus of $500 \mathrm{~W}$ could not be connected to the PVP output unless other apparatus are switched off and there is enough PVP generation (Fig. 4). In fact, in case 1 all apparatus of $100 \mathrm{~W}$ to $400 \mathrm{~W}$ are switched off to give the chance to apparatus of $500 \mathrm{~W}$ to be connected to PVP output. However, in case 2, the apparatus of $500 \mathrm{~W}$ is switched off and as a consequence any other apparatus will be connected to PVP output, respecting management criteria $(\S 2)$, as soon as it is switched on.

Approach valorisation: The valorisation of the designed system consists of daily and monthly assessments.

Daily assessment: The approach assessment is ensured by the establishment of a daily power audit. Figure 5 plots in real time the curves of the PVP related powers $\left(\mathrm{PVP}_{\mathrm{G}}\right.$ : generated, consumed: $\mathrm{PVP}_{\mathrm{C}}$, lost: $\left.\mathrm{PVP}_{\mathrm{L}}\right)$ and of the power load from grid (GLP) during the four chosen representative days (\$4). It is noted that the curve of $\mathrm{PVP}_{\mathrm{C}}$ follows the variations of $\mathrm{PVP}_{\mathrm{G}}$ in order to minimise $\mathrm{PVP}_{\mathrm{L}}$. Similarly, GLP decreases considerably 
Am. J. Applied Sci., 4 (2): 60-65, 2007

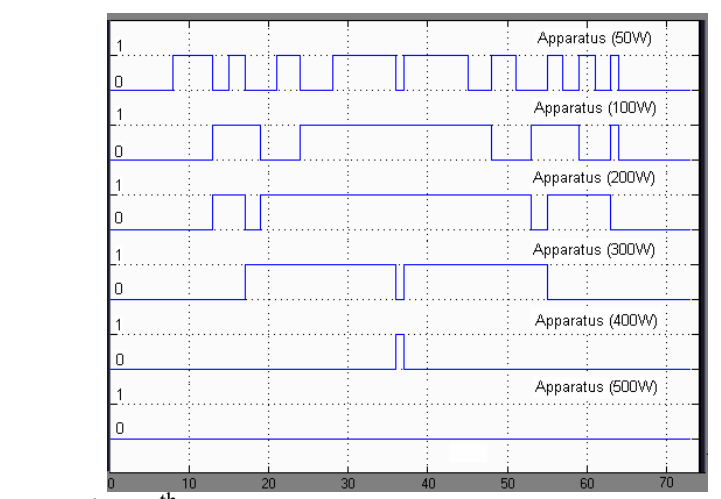

March, $14^{\text {th }} 2005$

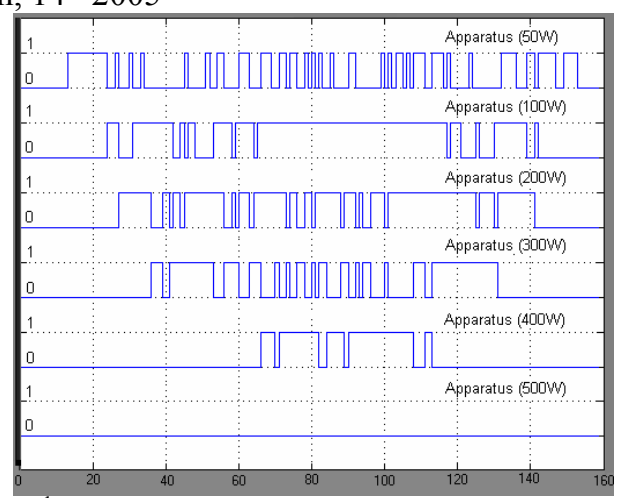

June, $28^{\text {th }} 2005$

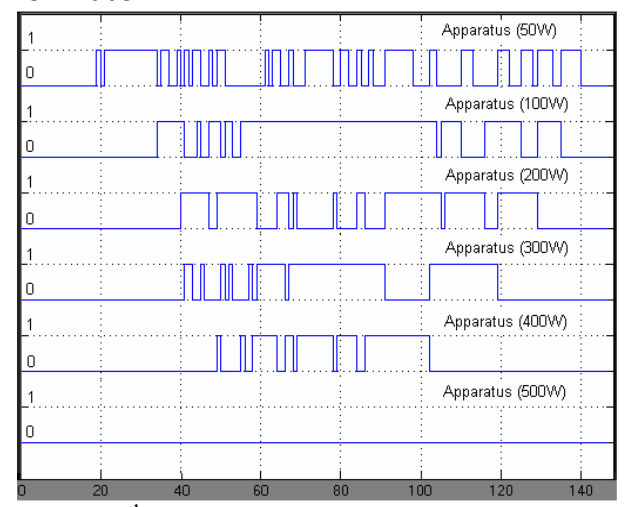

September, $23^{\text {th }} 2005$

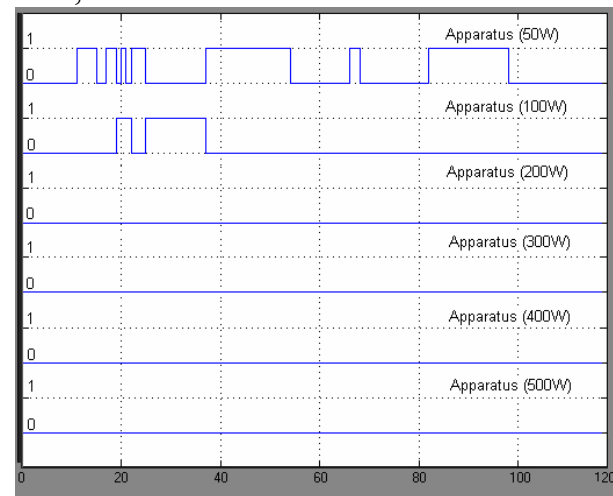

December, $10^{\text {th }} 2005$

Fig. 3:Timing of commands given to apparatus relays (all apparatus switched on). X_axis: 1 unit $=$ $5 \mathrm{mn}$ of the daylight. Y axis: 0: apparatus connected to PVP output.1: apparatus connected to grid

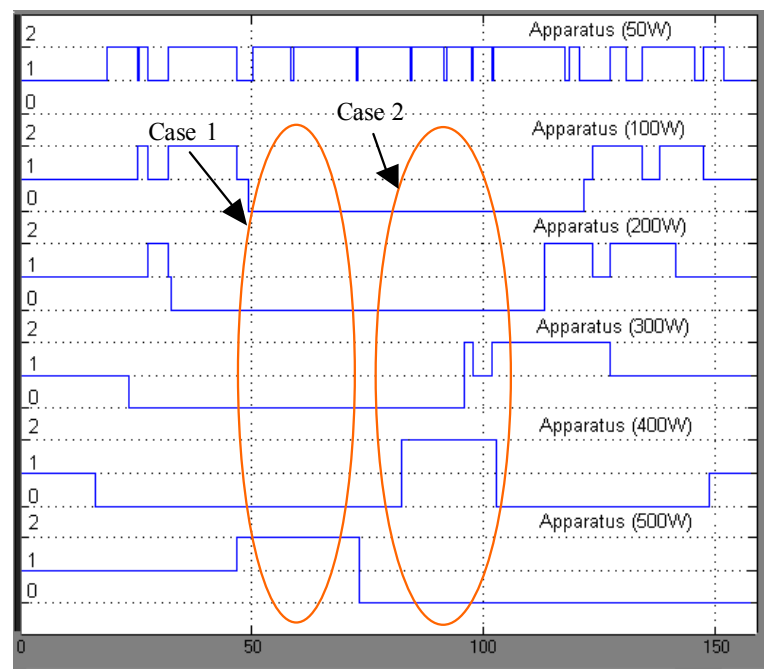

August, $8^{\text {th }} 2005$

Fig. 4:Timing of relays commands (apparatus manipulated). $X$ axis: Time: 1 unit $=5 \mathrm{mn}$ of the daylight. Y_axis: Apparatus state: 0: switched off. 1: connected to grid. 2: connected to PVP output

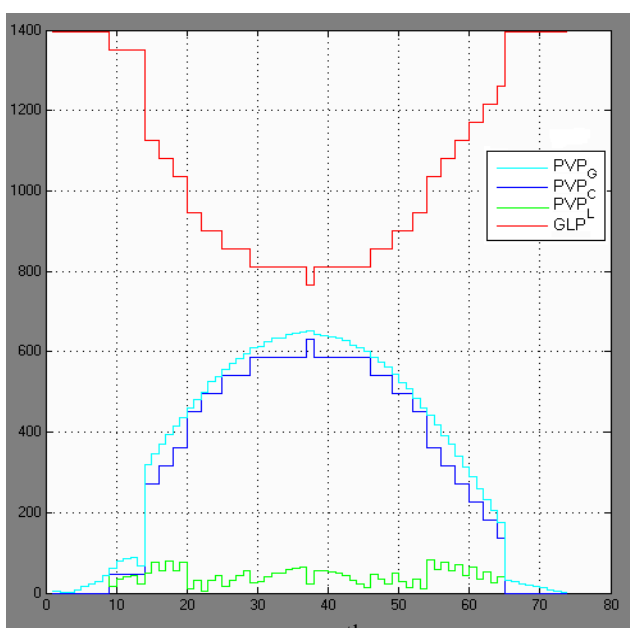

March, $14^{\text {th }} 2005$

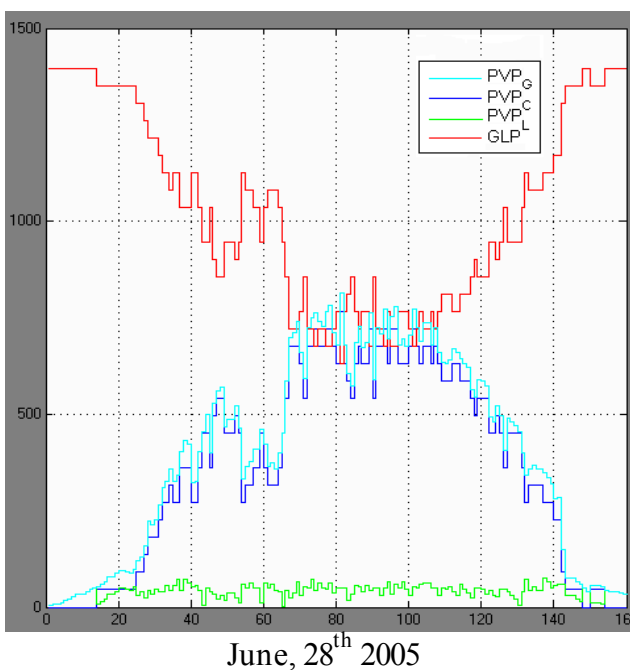


Table 1: The monthly effectiveness coefficient

\begin{tabular}{|c|c|c|c|c|c|c|c|c|c|c|c|c|}
\hline & Jan. & Feb. & Mar. & Apr. & May & Jun. & Jul. & Aug. & Sep. & Oct. & Nov. & Dec \\
\hline $\mathrm{PVP}_{\mathrm{GE}}$ & 86,2 & 98,8 & 129,1 & 135,2 & 148,3 & 149,4 & 156,4 & 161,3 & 136,9 & 123,3 & 92,5 & 78,6 \\
\hline $\mathrm{PVP}_{\mathrm{CE}}$ & 69,8 & 85,7 & 115,8 & 120,2 & 129,8 & 133,7 & 139,2 & 145,4 & 122,2 & 109,5 & 79,3 & 62,8 \\
\hline $\mathrm{PVP}_{\mathrm{LE}}$ & 16,4 & 13,1 & 13,3 & 15 & 18,5 & 15,7 & 17,2 & 15,9 & 14,7 & 13,8 & 13,2 & 15,9 \\
\hline$\eta \%$ & 81,0 & 86,7 & 89,7 & 88,9 & 87,5 & 89,5 & 89 & 90,1 & 89,3 & 88,8 & 85,7 & 79,9 \\
\hline
\end{tabular}

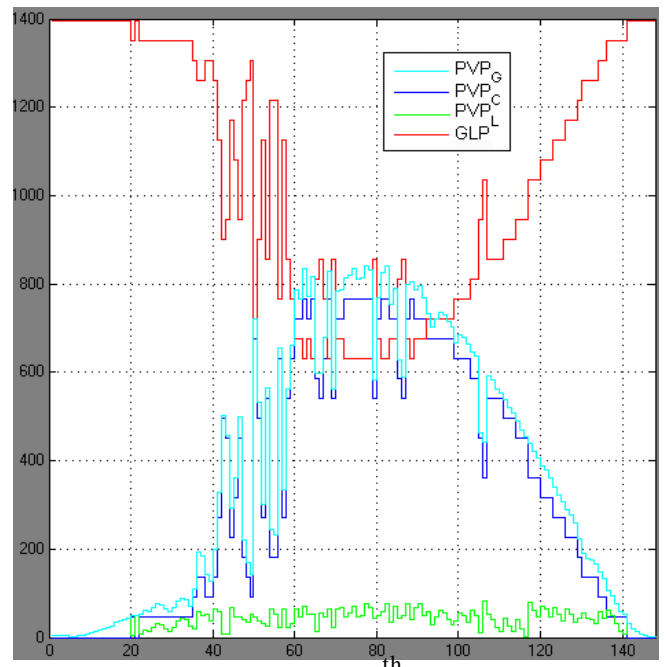

September, $23^{\text {th }} 2005$

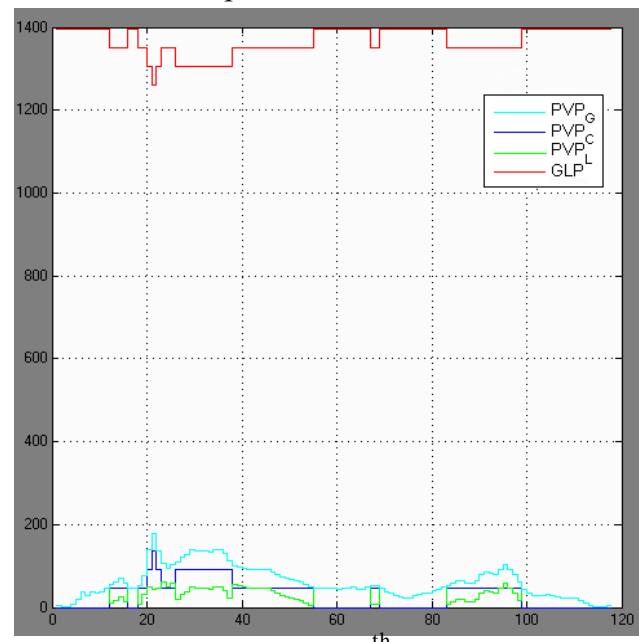

December, $10^{\text {th }} 2005$

Fig. 5: The daily power audit. $X \_$axis: 1 unit $=5 \mathrm{mn}$ of the daylight/ Y_axis: the power (W)

around midday especially during days of sunny seasons. These interpretations confirm the approach contribution in term of energy save and management for the whole installation.

Monthly assessment: The same study was renewed to form a monthly energy balance (Fig. 6) so as to prove the effectiveness of the management approach. All PVP related powers are integrated over daylight (from sunrise (SR) to sunset (SS)). Obtained energies are cumulated over the month length (ML) to compute PVP monthly energies (generated: $\mathrm{PVP}_{\mathrm{GE}}$, consumed: $\mathrm{PVP}_{\mathrm{CE}}$, lost: $\left.\mathrm{PVP}_{\mathrm{LE}}\right)$ as follows:

$$
\begin{aligned}
P V P_{G E} & =\sum_{j=1}^{M L} \int_{S R(j)}^{S S} P V P_{G}(t) d t ; \\
P V P_{C E} & =\sum_{j=1}^{M L} \int_{S R(j)}^{S S(j)} P V P_{C}(t) d t ; \\
P V P_{L E} & =\sum_{j=1}^{M L} \int_{S R(j)}^{S S(j)} P V P_{L}(t) d t
\end{aligned}
$$

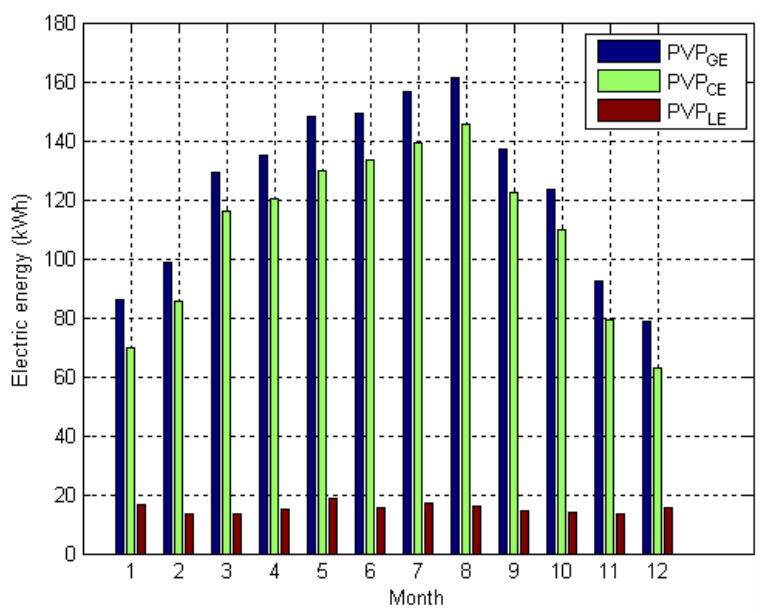

Fig. 6: The monthly energy balance

While the electric energy produced by the PVP varies between 80 and $160 \mathrm{kWh} /$ month, the electric energy consumed from the PVP varies between 65 and 145 $\mathrm{kWh} /$ month which involves an unused energy about 15 $\mathrm{kWh} /$ month. This lost energy is generally produced during the sunrise and sunset times where PVP generation is insufficient $(<50 \mathrm{~W})$ to supply energy for even the lower power apparatus. A second valorisation consists of the calculation of a monthly effectiveness coefficient defined by:

$\eta \%=\frac{P V P_{G E}-P V P_{L E}}{P V P_{G E}} \times 100=\frac{P V P_{C E}}{P V P_{G E}} \times 100$

Table 1 gives the $(\eta \%)$. This coefficient is almost constant through the months of the year and it varies between $80 \%$ and $90 \%$ which justifies the continuous energy save contribution of the proposed solution.

\section{CONCLUSION}

The efficient management of the energy produced by a conversion system depends on consumption needs 
on the one hand and on the supplied energy (generated by the conversion system) on the other hand. Herein the energy produced by a PVP of $1000 \mathrm{Wp}$ is optimally managed to provide a complementary energy for household apparatus so as to offer a maximum energy saving. The management approach consists of deciding the optimal connection mode of domestic apparatus either to PVP output or to grid. Decision is made on the basis of PVP generation and apparatus states according to criteria which offer a maximum exploitation of the energy delivered by the PVP during daylight. The system is implemented and tested during 2005. A carried out energetic audit confirms that $90 \%$ of PVP generated energy is brought to the installation as energy save.

\section{REFERENCES}

1. Fanny, A.H., B.P. Dougherty and M.W. Davis, 2001. Measured performance of building integrated photovoltaic panels. Solar Energy: The power to choose, Forum 2001 Washington, D.C.

2. Xu, M., Roderik, V.N. Melnik and U. Borup, 2004. Modelling anti-islanding protection devices for photovoltaic systems. Renewable Energy, 29: 2195-2216.

3. Kawamura, H., K. Naka and N. Yonekura, 2003. Simulation of I-V characteristics of a PV module with shaded PV cells. Solar Energy Materials \& Solar Cells, 75: 613-621.

4. Gergaud, O., B. Multon and H. Ben Ahmed, 2002. Analysis and experimental validation of various photovoltaic system models. $7^{\text {th }}$ Intl. ELECTRIMACS Congress, Montréal.

5. De Soto, W., S.A. Klein and W.A. Beckman, 2006. Improvement and validation of a model for photovoltaic array performance. 80: 78-88.

6. Gong, X. and M. Kulkarni, 2005. Design optimization of a large scale rooftop photovoltaic system. Solar Energy, 78: 362-374.

7. Kang, F.S., S.E. Cho and S.J0 Park, 2005. A new control scheme of a cascaded transformer type multilevel inverter for a residential photovoltaic conditioning system. Solar Energy, 78: 727-738.

8. Abdullah, A.H., A.A. Ghoneim, A.Y. AlHasen, 2002. Assessment of grid connected photovoltaic systems in the Kuwaiti climate. Renewable Energy, 26: 189-199.
9. Sheriff, F., D. Turcotte and M. Ross, 2003. PV Toolbox: A comprehensive set of PV system components for the MATLAB/SIMULINK Environment. SESCI'2003 Queen's University Canada.

10. Manolakos, D., G. Papadakis, D. Papantonis and S. Kyritsis, 2001. A simulation-optimisation programme for designing hybrid energy systems for supplying electricity and fresh water through desalination to remote areas. Applied Energy, pp: 679-704.

11. Muselli, M., G. Notton, P. Poggi and A. Louche, 2000. PV-hybrid power systems sizing incorporating battery storage: An analysis via simulation calculations. Renewable Energy, 20: 17.

12. Shouten, N.J., M.A. Salman and N.A. Kheir, 2003. Energy management strategies for parallel hybrid vehicles using fuzzy logic. Control Engineering Practice, 11: 171-177.

13. ElShatter, T.F., M.N. Eskandar, M.T. Elhagry, 2006. Energy flow and management of hybrid wind/PV/fuel cell generation system. Energy Conversion and Management, 47: 1264-1280.

14. Chaabene, M. and M. Annabi, 1998. Dynamic thermal model for predicting solar plant adequate energy management. Energy Conversion and Management, 39: 349-355.

15. Ishengoma, F.M. and L.E. Norum, 2002. Design and implementation of a digitally controlled standalone photovoltaic power supply. Nordic Workshop on Power and Industrial Electronics, 1214 Aug., NORPIE/2002, Stockholm, Sweden.

16. Beccali, M., M. Cellura and D. Ardente, 1998. Decision making in energy planning: The electre multicriteria analysis approach compared to a fuzzy-sets methodology. Energy Conversion and Management, 39: 1869-1881.

17. Jeong, K.S., W.Y. Lee and C.S. Kim, 2005. Energy management strategies of a fuel cell/battery hybrid system using fuzzy logics. J. Power Sources, 145: 319-326. 